\title{
Light at the end of the tunnel?
}

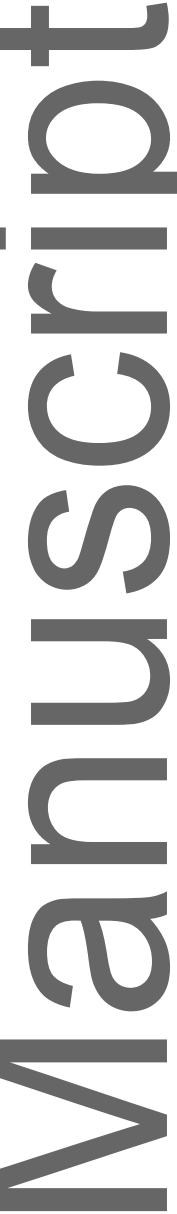

D.A. Machado-Aranda ${ }^{1}, \mathrm{~K}$. Raghavendran ${ }^{1}$

1-Division of Acute Care surgery, Department of Surgery

University of Michigan

Circadian rhythms respond primarily to darkness and light. Their importance in critical illness, though recognized for some time, remains poorly understood. In this edition of JLB, Griepentrog et al report that using a clinically relevant model of Klebsiella pneumoniae, blue spectrum light enhanced immune competence. ${ }^{1}$

Klebsiella pneumoniae (KP) account for a significant proportion of community and hospital acquired pneumonia. They are particularly virulent as they cause significant alveolar necrosis and have the potential to cause septicemia. ${ }^{2}$ Additionally, Carbapenam-resistant $K P$ is associated with a mortality of $45-60 \%$. Due to the alarming increase in Carbapenam-resistant Enterobacteriaceae (CRE), of which $K P$ comprises the majority of infections, the Centers for Disease Control (CDC) have designated these bacteria as an urgent threat to public health. ${ }^{3}$ Therefore, new therapeutic strategies are urgently needed.

Blue light is part of the spectral light that primarily stimulates the proteins involved in the circadian rhythm, located within the supra-chaismatal nucleus. These set of studies complement previous studies from the same authors that show that blue light reduced inflammation and organ injury in a sterile model of ischemia-reperfusion injury. ${ }^{4}$ The authors first demonstrate that blue light reduces the heart rate as well as heart rate variability suggesting a predominant parasympathetic stimulation. Using a lethal model of $K P$ that is introduced through intra-tracheal inoculation, the authors then show that blue light selectively improves survival and bacterial clearance from all the organs including the lung and cause a reduction in bacteremia.

Correspondingly, blue light is accompanied by reduced alveolar neutrophil influx and reduction in lung inflammation. Blue light failed to show similar results in transgenic mice $\left(V s \times 2^{-/-}\right)$with absence of the optic nerve and using $\alpha$-bungaro toxin, a competitive inhibitor of nicotinic cholinergic receptors, the authors demonstrated that blue light functioned through an optic-cholinergic pathway. Finally, the authors note that circadian clock protein Rev-Erb- $\alpha$ is primarily involved in these processes by using biochemical activation with agonist SR9009 resulting in enhanced bacterial elimination in-vivo and improved macrophage phagocytic activity in in-vitro studies. A subsequent study using Knock in or knock out animals with Rev-Erb- $\alpha$ would be complementary to this study as the synthetic agonists have been known to have multiple off target effects. ${ }^{5}$

It is interesting to note that Rev-Erb-a, a portion of the feedback loop regulating the CLOCK proteins involved in the circadian regulation also take part in regulation of metabolic processes. Rev-Erb- $\alpha$ has been found to modulate lipid, glucose, bile acid metabolism, adipogenesis, and generation of acute inflammatory response ${ }^{6}$.

Additionally, Rev-Erb- $\alpha$ has been shown to modulate metabolism of triglyceride-rich lipoproteins that are associated with increased risk of cardiovascular disease through

This is the author manuscript accepted for publication and has undergone full peer review but has not been through the copyediting, typesetting, pagination and proofreading process, which may lead to differences between this version and the Version of Record. Please cite this article as doi:

10.1002/jlb.10513.

This article is protected by copyright. All rights reserved. 
modulation of inflammation in atherosclerosis. ${ }^{7}$ Several studies have reported on novel natural ${ }^{8}$ and synthetic ligands for Rev-Erb- $\alpha .{ }^{9}$ Modulation of these ligands may represent a promising target for the treatment of metabolic abnormalities resulting from chronic aberrant circadian rhythms.

However, history teaches us that regulation of inflammation could be a double edged sword. A robust inflammatory response with appropriate phenotypic characterization of alveolar macrophages is needed for bacterial clearance. Moreover, there are conflicting sets of data regarding Rev-Erb- $\alpha$. In human macrophages, Rev-Erb- $\alpha$ has been shown to repress the induction of toll-like receptor (TLR)- $4,{ }^{10}$ the primary TLR involved with gram-negative bacterial pathogenesis. Finally, as the authors have acknowledged, studies in predominantly nocturnal animals such as mice may not have any human translational significance. Clinical studies in critically ill patients with blue light augmentation are eagerly awaited and it remains to be seen if blue light represents the light at the end of the tunnel or is just a train coming over from the other end.

\section{References}

1. Griepentrog JE, Zhang X, Lewis AJ, et al. Frontline Science: Rev-Erbalpha links blue light with enhanced bacterial clearance and improved survival in murine Klebsiella pneumoniae pneumonia. J Leukoc Biol. 2019.

2. Guidelines for the Management of Adults with Hospital-acquired, Ventilator-associated, and Healthcare-associated Pneumonia. Am J Respir Crit Care Med. 2005;171(4):388-416.

3. CDC. CRE-carbapenam resistant enetrobacteriacea. CDC mortality and morbidity. 2016; https://www.cdc.gov/hai/organisms/cre/cre-patientgeneral.html.

4. Yuan $\mathrm{D}$, Collage $\mathrm{RD}$, Huang $\mathrm{H}$, et al. Blue light reduces organ injury from ischemia and reperfusion. Proc Natl Acad Sci U S A. 2016;113(19):5239-5244.

5. Solt LA, Wang Y, Banerjee $S$, et al. Regulation of circadian behaviour and metabolism by synthetic REV-ERB agonists. Nature. 2012;485(7396):62-68.

6. Duez H, Staels B. Rev-erb-alpha: an integrator of circadian rhythms and metabolism. J Appl Physiol (1985). 2009;107(6):1972-1980.

7. Raspe $\mathrm{E}$, Duez $\mathrm{H}$, Mansen $\mathrm{A}$, et al. Identification of Rev-erbalpha as a physiological repressor of apoC-III gene transcription. J Lipid Res. 2002;43(12):2172-2179.

8. Reinking J, Lam MM, Pardee K, et al. The Drosophila nuclear receptor e75 contains heme and is gas responsive. Cell. 2005;122(2):195-207.

9. Kojetin DJ, Burris TP. REV-ERB and ROR nuclear receptors as drug targets. Nat Rev Drug Discov. 2014;13(3):197-216.

10. Fontaine $\mathrm{C}$, Rigamonti $\mathrm{E}$, Pourcet $\mathrm{B}$, et al. The nuclear receptor Rev-erbalpha is a liver $\mathrm{X}$ receptor (LXR) target gene driving a negative feedback loop on select LXR-induced pathways in human macrophages. Mol Endocrinol. 2008;22(8):1797-1811.

This article is protected by copyright. All rights reserved. 
